\title{
Effect of crown to implant ratio and implantoplasty on the fracture resistance of narrow dental implants with marginal bone loss: an in vitro study
}

Bruno Leitão-Almeida ${ }^{1 *} \mathbb{D}$, Octavi Camps-Font ${ }^{2}$, André Correia ${ }^{1}$, Javier Mir-Mari' ${ }^{2}$, Rui Figueiredo ${ }^{2}$ and Eduard Valmaseda-Castellón ${ }^{2}$

\begin{abstract}
Background: Peri-implantitis is a biological complication that affects soft and hard tissues around dental implants. Implantoplasty (IP) polishes the exposed implant surface, to decontaminate it and make it less prone to bacterial colonization. This study investigates whether a higher clinical crown-to-implant-ratio (CIR) reduces implant fracture resistance and whether implants are more fracture-prone after IP in the presence of 50\% of bone loss.

Methods: Forty-eight narrow platform $(3.5 \mathrm{~mm}) 15 \mathrm{~mm}$ long titanium dental implants with a rough surface and hexagonal external connection were placed in standardized bone-like resin casts leaving $7.5 \mathrm{~mm}$ exposed. Half were selected for IP. The IP and control groups were each divided into 3 subgroups with different clinical CIRs (2:1, 2.5:1 and 3:1). The implant wall width measurements were calculated using the software ImageJ v.1.51 through the analysis of plain $\mathrm{x}$-ray examination of all the samples using standardized mounts. A fracture test was performed and scanning electron microscopy was used to evaluate maximum compression force $\left(F_{\max }\right)$ and implant fractures.

Results: IP significantly reduced the implant wall width $(P<0.001)$ in all reference points of each subgroup. $F_{\max }$ was significantly higher in the 2:1 subgroup (control $=1276.16 \mathrm{~N} \pm 169.75 ; \mathrm{IP}=1211.70 \mathrm{~N} \pm 281.64$ ) compared with the $2.5: 1$ (control $=815.22 \mathrm{~N} \pm 185.58, P<0.001 ; \mid \mathrm{P}=621.68 \mathrm{~N} \pm 186.28, P<0.001$ ) and the $3: 1$ subgroup (control $=606.55 \mathrm{~N} \pm 111.48, P<0.001 ; \mathrm{P}=465.95 \mathrm{~N} \pm 68.57, P<0.001$ ). Only the $2.5: 1$ subgroup showed a significant reduction $(P=0.037)$ of the $F_{\max }$ between the controls and the IP implants. Most fractures were located in the platform area. Only 5 implants with IP of the 2:1 CIR subgroup had a different fracture location (4 fractures in the implant body and 1 in the prosthetic screw).

Conclusions: IP significantly reduces the fracture resistance of implants with a 2.5:1 CIR. The results also suggest that the CIR seems to be a more relevant variable when considering the resistance to fracture of implants, since significant reductions were observed when unfavorable CIR subgroups (2.5:1 and 3:1 CIR) were compared with the 2:1 CIR samples.
\end{abstract}

Keywords: Peri-implantitis, Dental implants, Compressive strength, Titanium, Implantoplasty

*Correspondence: bamalmeida@ucp.pt

${ }^{1}$ Faculty of Dental Medicine, Center for Inter-Disciplinary Research

in Health (CIIS), Universidade Católica Portuguesa, Estrada da

Circunvalação, 3504-505 Viseu, Portugal

Full list of author information is available at the end of the article

\section{Background}

Implant failure appears to have several causes: biological, mechanical or iatrogenic [1-3]. Peri-implantitis (PI) is one of the major concerns among clinicians, as it may 
affect $34 \%$ of patients and $21 \%$ of implants and lead to implant loss [4].

Several approaches to implant surface decontamination have been studied. They include air-powder abrasion, ultrasonic and manual debridement (using plastic, carbon stainless steel, graphite or titanium curettes), implantoplasty (IP), laser therapy and sterile saline rinses, among others [5-8]. Mechanical debridement has also been complemented by the use of a number of substances, such as citric acid, hydrogen peroxide, cetylpyridinium chloride, tetracycline, ethylenediamine tetraacetic acid or chlorhexidine [9]. IP is a common procedure that consists of polishing rough implant surfaces outside the bony envelope, making them less prone to bacterial accumulation, as surface roughness may be risk factor for peri-implant disease. IP is effective in the long term for arresting bone loss caused by PI, both alone and in combination with surgical regenerative procedures and does not seem to be associated with any biological or mechanical complication of importance [9-13]. However, thermal increases during the procedure that could affect the bone, lower resistance to fractures due to reducing the thickness of the implant walls, and the local and systemic biological repercussions that the dispersion of titanium particles might have in the long term have been signaled as potential problems of IP performance [14-19].

Increasing bone loss due to PI was shown to increase clinical crown-to-implant ratio (CIR), which, in turn, was reported to reduce the resistance to fracture of intact dental implants $[20,21]$. Also, IP, which is often used as a part of the treatment of PI, reduces the thickness of the implant walls and might weaken the strength of implants [15]. Since the effect of the CIR on implants treated with IP has not been addressed yet, it would be of great interest to assess whether IP is a safe technique when implants with high CIRs are involved.
Furthermore, since the maximum failure strength of bone level implants is expected to remain high after IP, narrow implants were selected to simulate an unfavorable scenario. Indeed, according to a recent report by Bertl et al., narrow diameter implants have a significant lower resistance strength compared with regular diameter implants [22].

The main study hypothesis was that a high CIR negatively affects the fracture resistance of narrow implants treated with IP in a situation of $50 \%$ bone loss. Therefore, the main objectives of this research were: (1) to analyze whether an increased CIR reduces the fracture resistance of implants with IP versus control implants, and (2) to assess whether implants subjected to IP are more prone to fracture in comparison with control implants, regardless of the CIR, in the presence of $50 \%$ bone loss. A secondary aim was to describe the changes in implant wall width after IP.

\section{Materials and methods}

An in vitro study was conducted using 48 type $\mathrm{V}$ titanium narrow platform implants, $3.5 \mathrm{~mm}$ in diameter and $15 \mathrm{~mm}$ long, with a rough surface and a hexagonal external connection (Ocean E.C., Avinent Implant System S.L., Santpedor, Spain). Half of the sample was randomly allocated to the IP group. The apical half of each implant was inserted, leaving $7.5 \mathrm{~mm}$ exposed, in standardized bone-like resin casts (EA 3471 A and B Loctite ${ }^{\circledR}$, Henkel AG and Company, Düsseldorf, Germany) with $a \geq 3 \mathrm{GPa}$ modulus of elasticity in accordance with International Organization for Standardization (ISO) standard 14801:2016 (third edition) [23]. Both groups were divided into 3 subgroups of 8 implants each, which received screwed hemispherical loading abutments of one of three heights: $7.5 \mathrm{~mm}, 11.25 \mathrm{~mm}$ and $15 \mathrm{~mm}$, simulating clinical CIR of 2:1, 2.5:1 and 3:1, respectively (Fig. 1).

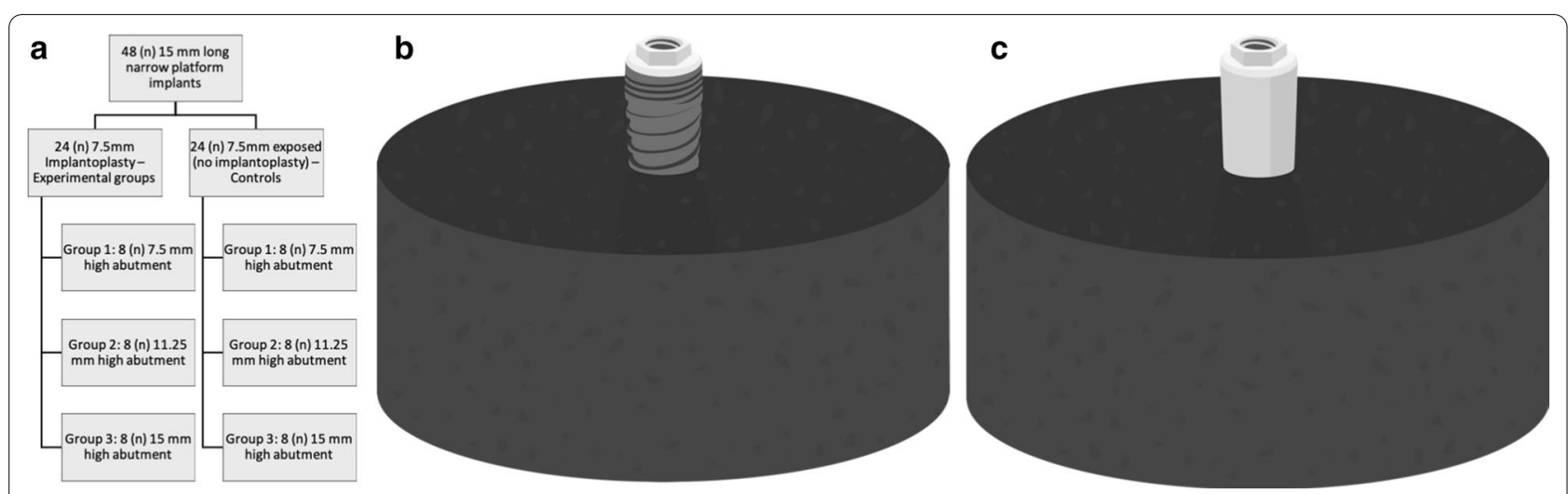

Fig. 1 a Study design, groups and subgroups; $\mathbf{b}$ sample before IP; c sample after IP 


\section{Implantoplasty}

IP of the exposed implant surface was performed using a high-speed air-powered hand piece (Bora Blackline LED, Bien-Air Dental SA, Langgasse, Switzerland) with an abutment protecting the connection. After removing the threads of the exposed portion of the implants, using an oval-shape tungsten carbide bur (H379 314,023; Komet Dental, Lemgo, Germany), the surface was polished with two-step silicon carbide polishers (9618,314,030 and 9608,314,030; Komet Dental, Lemgo, Germany) until it was macroscopically flat and smooth. A new set of burs was used for each sample. The procedure was performed by an experienced surgeon with $2.8 \times$ magnification loupes (Galilean HD and Focus ${ }^{\mathrm{TM}}$ LED 6000 k, ExamVision ApS, Samsø, Denmark), under copious water irrigation and adequate light conditions, similar to a clinical scenario, although the cast was held by the operator and turned by hand. The time spent on each procedure was recorded. When the IP procedure was finished, the surface was cleaned with water and dried with air.

\section{Radiographic implant wall width measurements}

The implant wall width was measured through plain $x$-ray examination of all the samples, in the initial position and rotated through $120^{\circ}$ and $240^{\circ}$, using standardized mounts. All the measurements were made using ImageJ v.1.51 (National Institutes of Health, Bethesda, Maryland, USA), based on a fixed $1.9 \mathrm{~mm}$ reference provided by the manufacturer. A calibrated investigator (BLA) performed the examination with $400 \mathrm{X}$ amplification and searched for perforations of the implant walls. The measurements were made at the middle of the first (R1) and tenth (R2) threads and at the end of the prosthetic screw hole (R3), as shown in Fig. 2. To test intraexaminer agreement and consistency, the assessment of 6 randomly selected samples (54 measurements) was repeated after 2 weeks. The intraclass correlation coefficients were 0.96 (95\% confidence interval $(95 \% \mathrm{CI}) 0.93-0.98 ; P<0.001)$ and 0.96 (95\% CI $0.92-0.98 ; P<0.001)$, showing excellent reliability and consistency.

The mean value of the three measurements (rotation of $0^{\circ}, 120^{\circ}$ and $240^{\circ}$ ) was recorded for each location and implant. The measurements in the IP group were subtracted from those of their control analogues, thus obtaining the thinning of the implant for each variable.

\section{Fracture tests}

Metallic hemispherical load abutments $(n=48)$ were digitally designed, milled and screwed onto each implant according to subgroup (Fig. $3 \mathrm{a}-\mathrm{c}$ ), using prosthetic screws (Avinent ${ }^{\circledR}$ Implant System, Santpedor, Spain) at $32 \mathrm{~N} / \mathrm{cm}$, as recommended by the product manufacturer.

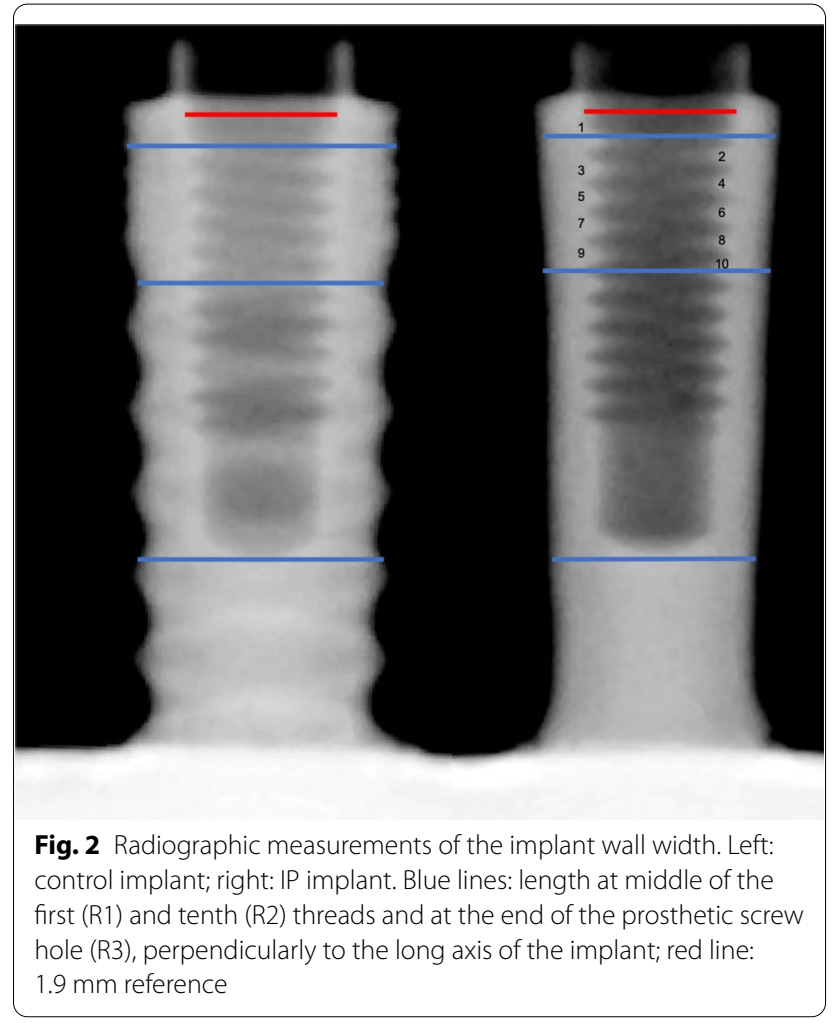

Tests to measure the maximum compression force $\left(\mathrm{F}_{\max }\right)$, i.e. the maximum force reached before implant fracture, were performed at a constant speed of $1 \mathrm{~mm} / \mathrm{min}$ with a universal servo-hydraulic mechanical testing machine (MTS Bionix 370 Load Frame, MTS ${ }^{\circledR}$, Eden Prairie, USA), applying a compression load to the implants with a 661.19H-03 MTS Load Cell of $15 \mathrm{kN}$ capacity. All the samples were held in the same device, a manufactured stainless-steel clamping jaw that allowed compression loads to be applied at a constant angle of $30^{\circ}$ from the vertical axis (Fig. 3d), in accordance with ISO 14801:2016 (third edition), except for the supracrestal $50 \%$ of the total implant length. The tests were monitored by the MTS Flextest 40 Controller (MTS ${ }^{\circledR}$, Eden Prairie, USA), which measured $F_{\max }$ and recorded real-time data.

Scanning electron microscopy (SEM) (Quanta 200 ${ }^{\circledR}$, FEI, Hilsboro, Oregon, United States) screening of the fractured implants was used to determine the fracture location.

\section{Statistical analysis}

The sample size calculation was performed with Stata v.14 software (StataCorp ${ }^{\circledR}$, College Station, USA). Considering $F_{\max }$ as the primary outcome measure, an analysis of variance with an $\alpha$ risk of 0.05 and a statistical power of $80 \%$ was performed. The mean fracture resistance values published by Gehrke [24] were used. 

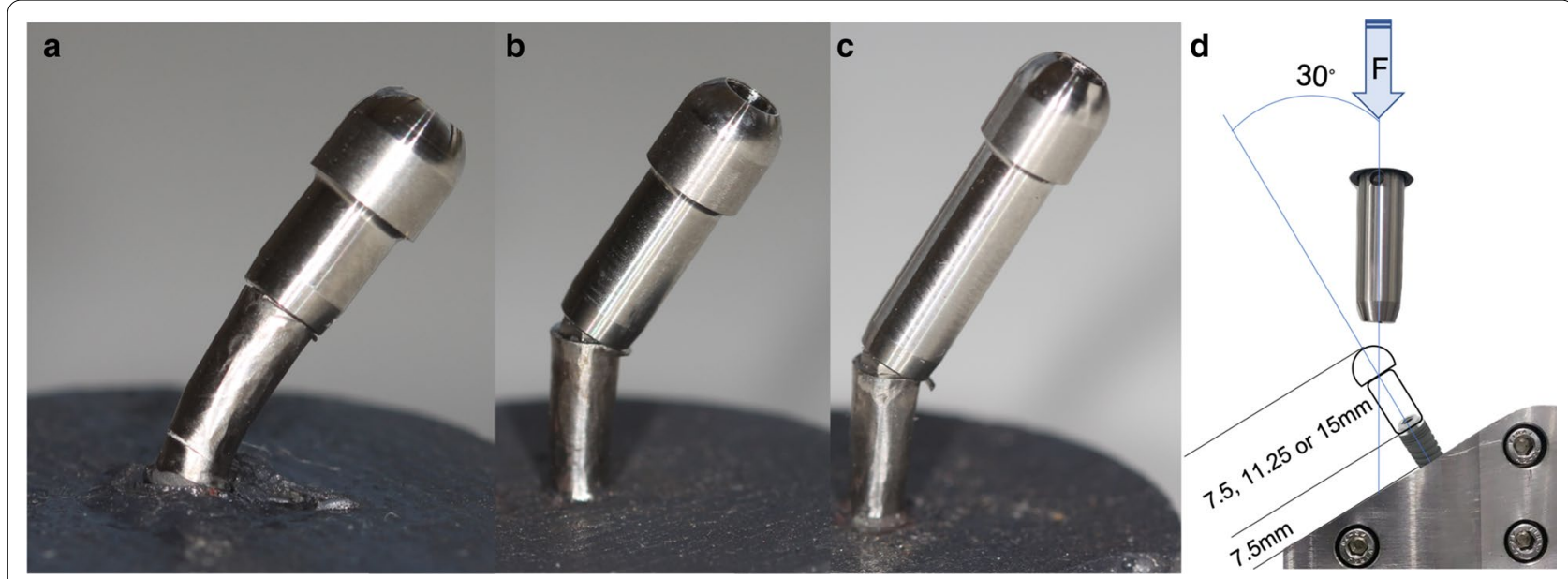

Fig. 3 IP samples after fracture test: a CIR 2:1, b CIR 2.5:1, c CIR 3:1, d fracture test diagram

Assuming a standard deviation of $500 \mathrm{~N}$, the sample size was established as 8 implants per subgroup.

The implant characteristics were presented as absolute and relative frequencies for categorical outcomes. The normality of the scale variables $\left(\mathrm{F}_{\max }\right.$ and implant wall width) was explored using the Shapiro-Wilk test, $\mathrm{P}-\mathrm{P}$ scatterplot graphs and box plots. Since $\mathrm{F}_{\max }$ and the implant wall width variables had a normal distribution the mean and the standard deviation (SD) were used.

To analyze the effects of the procedure (IP or control) on $\mathrm{F}_{\text {max }}$, of the crown length $(7.5,11.25$ or $15 \mathrm{~mm})$, and of the interaction between these two variables, a two-way ANOVA was performed. The ANOVA assumptions were assessed using the Shapiro-Wilk test for normality and Levene's test for homoscedasticity. Pairwise comparisons between subgroups, using Tukey's correction for multiplicity of contrasts, were made for each procedure and CIR. An unpaired $t$ test was used to identify differences in implant wall width between the control and IP groups at every reference point. In each area of interest, Pearson correlation coefficients were computed to quantify the correlation between implant wall width and $F_{\max }$. The associations between categorical variables were assessed with either Pearson's $\chi^{2}$ test or Fisher's exact test.

The statistical analysis was carried out with Stata14 software (StataCorp ${ }^{\circledR}$, College Station, TX, USA). The level of significance was set at $P<0.05$.

\section{Results}

\section{Fracture tests}

No correlations between implant wall width measurements and $F_{\max }$ were observed at any of the reference points (Table 1). Significant reductions in $F_{\max }$ between the control and IP implants were only found in the 2.5:1 CIR subgroup $(P=0.037)$, although all the IP samples showed less resistance to fracture than their respective controls (Table 2, Fig. 4). In both IP and control groups, the implants with a 2:1 CIR showed a higher $F_{\max }$ (control=1276.16 N土169.75; $\mathrm{IP}=1211.70 \mathrm{~N} \pm 281.64)$ than those with a $2.5: 1 \mathrm{CIR}$ (control=815.22 $\mathrm{N} \pm 185.58 ; \quad \mathrm{IP}=621.68 \mathrm{~N} \pm 186.28$ ) and $3: 1 \quad$ CIR $\quad$ (control=606.55 $\mathrm{N} \pm 111.48$; $\mathrm{IP}=465.95 \mathrm{~N} \pm 68.57$ ). No significant differences were observed between the 2.5:1 and 3:1 subgroups (control $P=0.064$; IP $P=0.206$ ) (Table 3, Fig. 4).

Most fractures $(n=43)$ were located in the platform area (Fig. 5a, b). The only 5 exceptions were found in implants with IP of the 2:1 CIR subgroup [4 fractures in the implant body (Fig. 5c) and 1 in the prosthetic screw (Fig. 5d)].

\section{Radiographic implant wall width measurements}

The mean reduction in the implant wall width after IP was 0.41 (CIR 2:1), 0.41 (CIR 2.5:1) and $0.37 \mathrm{~mm}$ (CIR $3: 1$ ) at R1; 0.46 (CIR 2:1), 0.45 (CIR 2.5:1) and $0.46 \mathrm{~mm}$ (CIR 3:1) at R2 and 0.45 (CIR 2:1), 0.43 (CIR 2.5:1) and $0.4 \mathrm{~mm}$ (CIR 3:1), at R3 (Table 1). In all the subgroups, IP was associated with a statistically significant reduction in width at reference points $1-3(P \leq 0.05$, independent samples $t$ test) and a similar value was found at each reference point $(P>0.05$ in all cases; one-way ANOVA) regardless of the crown length subgroup of the implant. No perforation of the inner threads of the implants were observed. 
Table 1 Implant wall width measurements $(\mathrm{mm})$ of IP and control samples at each reference point $(\mathrm{n}=48)$

\begin{tabular}{|c|c|c|c|c|c|}
\hline \multirow[t]{2}{*}{ Reference point } & \multirow{2}{*}{$\begin{array}{l}\text { Control } \\
\text { Mean (SD) }\end{array}$} & \multirow{2}{*}{$\begin{array}{l}\text { IP } \\
\text { Mean (SD) }\end{array}$} & \multirow[b]{2}{*}{ MD $(95 \% \mathrm{Cl})$} & \multirow[b]{2}{*}{$\begin{array}{l}\text { Independent samples } \\
t \text { test } \\
P \text { value }\end{array}$} & \multirow[b]{2}{*}{$\begin{array}{l}\text { ANOVA } \\
P \text { value }\end{array}$} \\
\hline & & & & & \\
\hline \multicolumn{6}{|l|}{ R1 (first thread) } \\
\hline $2: 1$ & $3.44(0.02)$ & $3.03(0.04)$ & $0.41(0.37-0.44)$ & $<0.001^{*}$ & 0.103 \\
\hline $2.5: 1$ & $3.44(0.01)$ & $3.03(0.04)$ & $0.41(0.38-0.45)$ & $<0.001^{*}$ & \\
\hline $3: 1$ & $3.45(0.02)$ & $3.08(0.04)$ & $0.37(0.33-0.40)$ & $<0.001^{*}$ & \\
\hline \multicolumn{6}{|l|}{ R2 (tenth thread) } \\
\hline $2: 1$ & $3.32(0.03)$ & $2.86(0.03)$ & $0.46(0.42-0.49)$ & $<0.001^{*}$ & 0.949 \\
\hline $2.5: 1$ & $3.31(0.02)$ & $2.86(0.04)$ & $0.45(0.41-0.49)$ & $<0.001^{*}$ & \\
\hline $3: 1$ & $3.34(0.03)$ & $2.89(0.06)$ & $0.46(0.41-0.50)$ & $<0.001^{*}$ & \\
\hline \multicolumn{6}{|c|}{ R3 (end of the prosthetic screw hole) } \\
\hline $2: 1$ & $3.07(0.03)$ & $2.62(0.06)$ & $0.45(0.40-0.50)$ & $<0.001^{*}$ & 0.163 \\
\hline $2.5: 1$ & $3.07(0.05)$ & $2.64(0.04)$ & $0.43(0.38-0.47)$ & $<0.001^{*}$ & \\
\hline $3: 1$ & $3.07(0.02)$ & $2.68(0.04)$ & $0.40(0.36-0.43)$ & $<0.001^{*}$ & \\
\hline
\end{tabular}

* Statistically significant difference

MD mean difference (Control—IP)

Table 2 Mean fracture strength (N) of the three CIR in the IP and control samples

\begin{tabular}{lllll}
\hline CIR & Control & IP & & \\
\cline { 4 - 5 } & Mean (SD) & Mean (SD) & MD (95\%Cl) & Adjusted P value \\
\hline $2: 1$ & $1276.16(169.75)$ & $1211.70(281.64)$ & $64.46(-117.17$ to 246.09$)$ & 0.478 \\
$2.5: 1$ & $815.22(185.58)$ & $621.68(186.28)$ & $193.54(11.91-375.17)$ & $0.037^{*}$ \\
$3: 1$ & $606.55(111.48)$ & $465.95(68.57)$ & $140.60(-41.03$ to 322.24$)$ & 0.126 \\
Total & $899.31(323.58)$ & $766.44(379.19)$ & $132.87(-71.95$ to 337.69) & 0.198 \\
\hline
\end{tabular}

* Statistically significant difference

MD mean difference (Control-IP)

\section{Discussion}

The main objectives of this in vitro study were to determine if narrow platform titanium implants with an external hexagonal connection subjected to IP were more prone to fracture in the presence of $50 \%$ bone loss, and to analyze if an increased CIR reduces the fracture resistance of implants with IP vs. control implants. The results of the present study show that IP only significantly reduced the $F_{\max }$ value in the 2.5:1 CIR subgroup. Besides, the mean total values of the 3 CIR subgroups showed no significant differences in $\mathrm{F}_{\max }$ between the control and IP samples (Table 2). CIR seems to be a much more relevant variable than IP, since both the IP and control implants showed significant reductions in $\mathrm{F}_{\max }$ in the 2.5:1 and 3:1 CIR subgroups when compared to the 2:1 subgroup (Table 3 ). Indeed, while IP reduced the mean fracture strength by $132.87 \mathrm{~N}$, a higher CIR (2.5:1 or 3:1) led to a mean difference of $525.48 \mathrm{~N}$ or $707.68 \mathrm{~N}$, respectively (Tables 2,3).
Similar in vitro protocols have been described previously, although with different implants, bone insertion levels and loading abutments [15, 24-27]. ShemtovYona et al. used intact $13 \mathrm{~mm}$-long implants with different widths and performed similar static tests, finding $F_{\max }$ values of $674 \mathrm{~N} \pm 57$ (3.3 mm implants), $952 \mathrm{~N} \pm 103$ (3.75 mm implants) and 1584 $\mathrm{N} \pm 115$ (5 mm implants), showing that implant wall width can affect resistance outcomes of intact implants [28]. On the other hand, Chan et al. using internal hexagonal implants, compared control and IP samples with different widths (3.75 and $4.7 \mathrm{~mm}$ ) and showed that IP did not significantly affect the resistance to fracture of 3.75 diameter implants (321.7 $\mathrm{N} \pm 21.4$ vs. $325.0 \mathrm{~N} \pm 20.7$ ) [15]. The fact that our report presents higher $F_{\max }$ values (Table 2) might be considered surprising since the implant diameter was inferior $(3.5 \mathrm{~mm})$, the CIRs were unfavorable and the simulated bone level was of $50 \%$. This discrepancy might be justified by the fact that our 


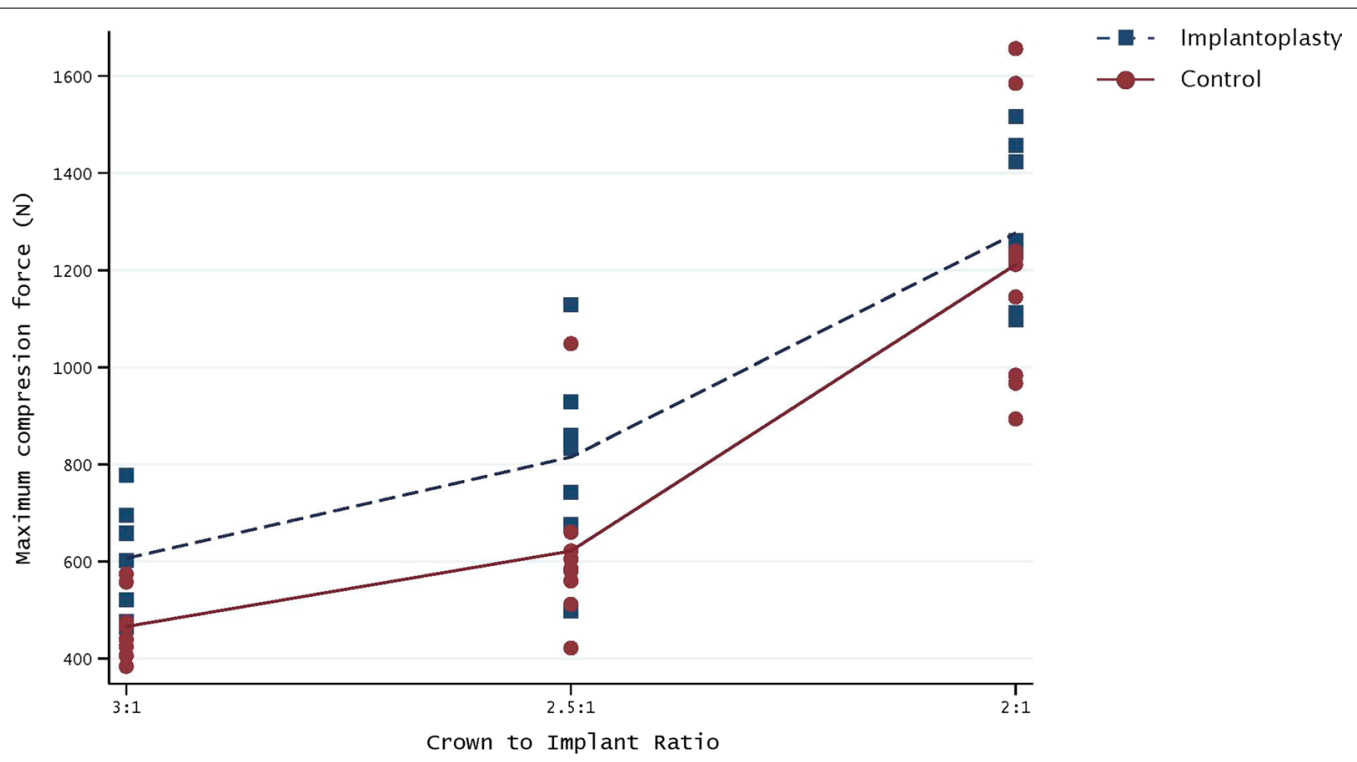

Fig. 4 Mean fracture strength $(\mathrm{N})$ of the three CIR ratios in the IP and control samples

Table 3 Mean fracture strength (N) of the IP and control groups in the three clinical CIR subgroups

\begin{tabular}{lllll}
\hline Group & CIR1 & CIR2 & MD $(\mathbf{9 5} \% \mathbf{C l})$ & Adjusted $P$ value \\
\hline Control & $2: 1$ & $2.5: 1$ & $460.94(242.27-679.60)$ & $<.001^{*}$ \\
& & $3: 1$ & $669.60(450.94-888.27)$ & $<.001^{*}$ \\
& $2.5: 1$ & $3: 1$ & $208.67(-9.99$ to 427.33$)$ & .064 \\
IP & $2: 1$ & $2.5: 1$ & $590.02(371.36-808.68)$ & $<.001^{*}$ \\
& & $3: 1$ & $745.75(527.09-964.41)$ & $<.001^{*}$ \\
Total & $2.5: 1$ & $3: 1$ & $155.73(-62.93$ to 374.39$)$ & .206 \\
& & $2.5: 1$ & $525.48(363.58-687.38)$ & $<.001^{*}$ \\
& $2.5: 1$ & $3: 1$ & $707.68(545.78-869.57)$ & $<.001^{*}$ \\
& & $182.20(20.30-344.10)$ & $<.001^{*}$
\end{tabular}

* Statistically significant difference

MD mean difference (CIR1-CIR2)

study employed external hexagonal implants which have shown higher $F_{\max }$ values in comparison with internal hexagonal implants in a recent published paper [26].

Significant differences in implant wall width due to the IP procedure were observed at all the reference points, but no perforations of the inner threads were found. The reduction in implant diameter at each of the 3 reference points ranged from $0.37 \mathrm{~mm}(95 \% \mathrm{CI}$ $0.33-0.40 \mathrm{~mm})$ to $0.46 \mathrm{~mm}(95 \%$ CI $0.41-0.50 \mathrm{~mm})$ in the IP test samples. Other authors with similar IP protocols have reported lower reductions [25, 29]. These discrepancies might be explained by differences in the degree of polishing, but are more likely to be the result of different implant geometries, namely thread depth and model. Thus, further studies with different implants should be carried out, since their design and material are likely to affect the implant's resistance to fracture. A similar extent of change was found at each reference point ( $P>0.05$ in all cases; one-way ANOVA), regardless of the crown length subgroup of the implant, showing the similarity of the IP across all these samples, which would indicate that the procedure should be easy to reproduce.

Previous reports have claimed that implant diameter affects stress fatigue behavior and that dental implants will attain a critical stress point at lower loadings when subjected to IP $[15,27,28]$. The present results corroborate this finding, as lower resistance to fracture was observed in the IP groups (Table 2). All the IP groups showed less $F_{\max }$ values than the control groups, although these differences were found to be significant in only one of the CIR subgroups (2.5:1). Hence, narrow platform implants seem to be structurally weakened by IP procedures, although the most relevant risk factor for mechanical complications in the presence of $50 \%$ of bone loss seems to be CIR, as the mean $F_{\max }$ values dropped to almost half between the $2: 1$ and 2.5:1 CIR subgroups (mean difference $590.02 \mathrm{~N}, 95 \% \mathrm{CI}: 371.36 \mathrm{~N}$ to $808.68 \mathrm{~N}$ ) and by $61.6 \%$ between $2: 1$ and 3:1 (mean difference $745.75 \mathrm{~N}, 95 \% \mathrm{CI}$ : $527.09 \mathrm{~N}$ to $964.41 \mathrm{~N}$ ) (Table 3). Bertl et al. [22] having obtained a statistically significant reduction of fracture resistance on IP implants, reported that the forces required to fracture or deform a narrow diameter implant with IP remained high and therefore, 

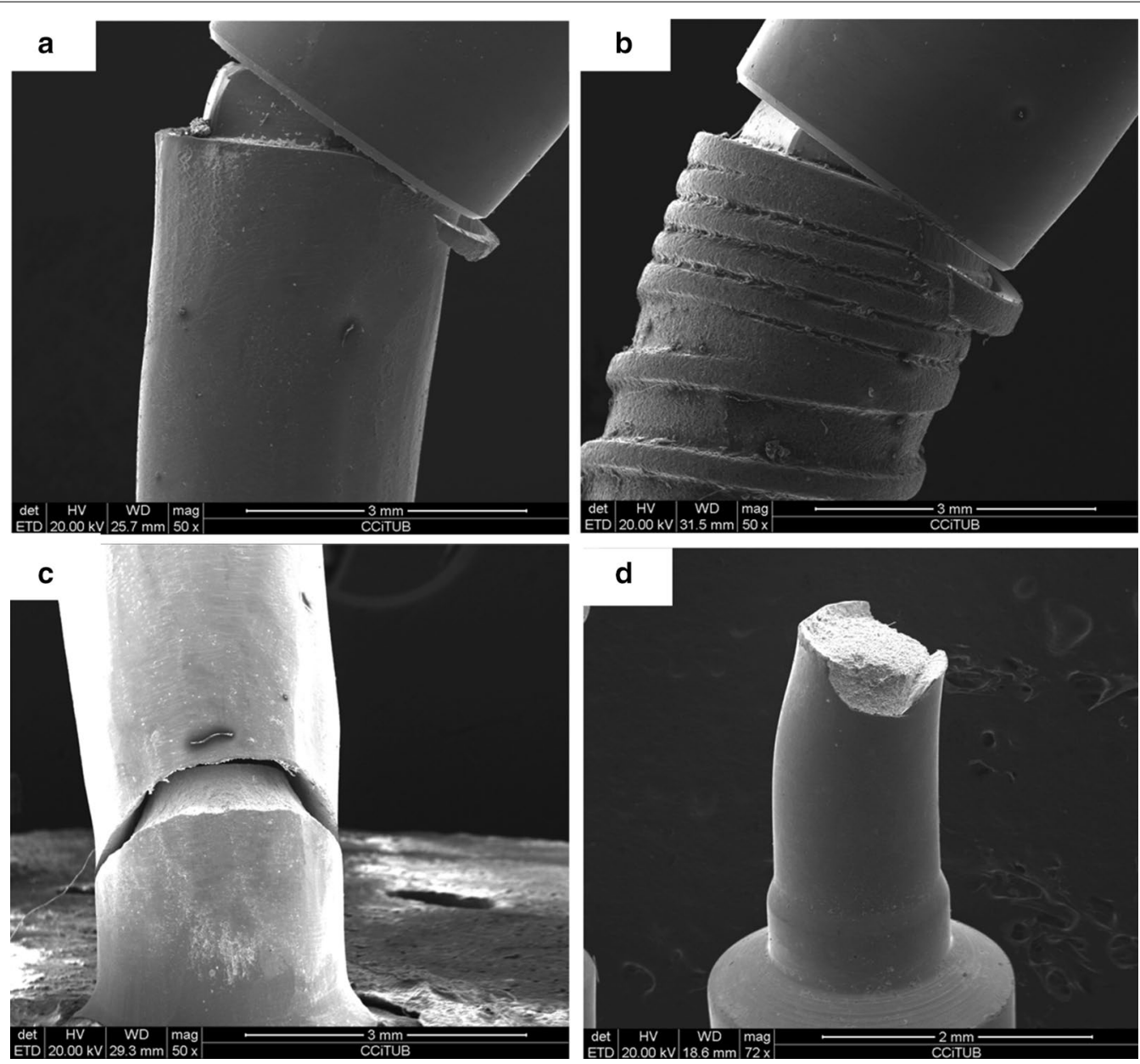

Fig. 5 SEM screening: a IP sample platform fracture; $\mathbf{b}$ control sample platform fracture; $\mathbf{c}$ IP sample body fracture; $\mathbf{d}$ prosthetic screw fracture;

this reduction has a limited clinical relevance in the majority of cases.

In both the IP and control groups, $\mathrm{F}_{\max }$ decreased with increasing CIR, although the only significant differences were between CIR 2:1 and the other two subgroups (Table 3). No significant differences between CIR 2.5:1 and 3:1 were observed despite the latter's resistance to fracture being lower in both the IP and control implants (Control: $815.22 \mathrm{~N}$ vs. $606.55 \mathrm{~N}$; IP: $621.68 \mathrm{~N}$ vs. $465.95 \mathrm{~N}$ ). This outcome might be related with the limited sample size and with the observed standard deviations. However, it is important to stress that the lowest resistance value was found in the 3:1 CIR subgroup with IP (465.95 N \pm 68.57$)$.

In the present study, the area mostly affected by fracture was the platform, which would suggest that the platform is more fragile than the body in narrow fixtures. While all the control implants broke at the platform, in the IP group with a 2:1 CIR some fractures occurred in the body $(\mathrm{n}=4)$ and prosthetic screw $(\mathrm{n}=1)$, suggesting that IP reduces the mechanical resistance of the implant body. However, when higher CIRs were tested the stress seemed to be directed towards the platform and the prosthetic connection, and therefore all the fractures occurred in this area. Other studies using regular platform implants have found that implants subjected to IP usually break at the implant body, and although IP does not seem to decrease the maximum compression force of regular diameter external connection implants significantly, it clearly weakens the implant body [25]. Upon testing different CIRs with $3.5 \mathrm{~mm}$ intact external hexagon implants, fracture screw and implant platform deformation have been reported along with reduced resistance to fracture with increasing CIR. Gehrke performed an in vitro study with 60 implants with 3 different connections and also concluded that increasing the crown height significantly reduces the resistance to loading [24]. According to this paper, the abutment connection type also seems to be a relevant variable in 
the fracture resistance of dental implants, since morse taper implants seem to be less prone to fracture than external and internal hexagonal connections. However, IP may alter these results. Indeed, a recently published paper compared the fracture resistance after IP of three connection designs and concluded that external hexagonal connection implants have a higher resistance to fracture [26]. Another variable that should be taken into consideration is the degree of bone loss. This factor might be relevant since it affects the clinical crown height [30].

The present study presents some limitations related to its in vitro design. Firstly, the IP procedures were performed by hand to simulate real-life conditions, instead of using a milling machine. Although this might compromise the standardization of the implant reduction slightly, it increased the external validity of the outcomes. Secondly, long implants $(15 \mathrm{~mm})$ were selected in order to assure adequate retention in the resin during the fracture tests. The length and 50\% exposure of the implant provide information especially for extreme bone loss cases. In addition, $3.5 \mathrm{~mm}$ wide implants were selected because previous reports have shown that narrower implants must be addressed carefully for IP [15]. Nevertheless, narrow implants are widely used and bone loss from PI can affect any implant. Consequently, these factors were considered valuable for understanding the threshold of fracture resistance. Although a $15 \mathrm{~mm}$ long implant with a $15 \mathrm{~mm}$ long restoration is not common, considering a bone level type implant it represents a standard 1:1 CIR. Also, when PI has caused the loss of $5 \mathrm{~mm}$ of bone, the 1:1 clinical CIR of a $10 \mathrm{~mm}$ long implant with a $10 \mathrm{~mm}$ long restoration becomes a clinical CIR of 3:1, similar to that of the $15 \mathrm{~mm}$ abutment subgroup in this study. In addition, the static compressive loads at a $30^{\circ}$ angle used for fracture testing do not replicate the daily complex oral function of patients [31]. However, the methodology employed complied with ISO guideline 14801:2016 (third edition), except for the vertical exposure of the implant, allowing comparison with previous studies. Nevertheless, future research should include dynamic fatigue tests to determine the clinical relevance of the fracture resistance encountered. According to Gibbs et al., the maximum human clenching force covers a wide range, from 98 to $1243 \mathrm{~N}$, and is affected by several factors including age, gender and tooth support [32]. The top of this range would fracture all the samples except for the controls with a 2:1 CIR [1276.16 N $(\sigma=169.75)]$.

Bite force seems to decrease from molar to premolar and to incisor. Maximum bite forces measured in male subjects are higher than those of female subjects according to Umesh et al. [33]. The same authors found maximum bite forces of $744 \mathrm{~N}$ in molars, $371 \mathrm{~N}$ in premolars and $320 \mathrm{~N}$ in incisors.

Considering the above outcomes and comparing them with the present data, IP procedures with a CIR of 2:1 (mean fracture strength $1211.70 \mathrm{~N} \pm 281.64$ ) would present a low fracture risk regardless of implant position, and fracture risk would be of concern after IP in molar regions with a CIR of 2.5:1 (mean fracture strength $621.68 \mathrm{~N} \pm 86.28$ ) or 3:1 (mean fracture strength $465.95 \mathrm{~N} \pm 68.57$ ).

In such cases, it would be advisable for clinicians to perform a risk-benefit analysis, since implant fractures are more likely to occur. Therefore, as the Young modulus of different titanium alloys and ceramic implants varies, further research is needed to determine the resistance to fracture of new materials used for dental implants.

\section{Conclusions}

IP significantly reduces the fracture resistance of implants with a $2.5: 1 \mathrm{CIR}$. The results also suggest that the CIR seems to be a more relevant variable when considering the resistance to fracture of implants, since significant reductions were observed when unfavorable CIR subgroups (2.5:1 and 3:1 CIR) were compared with the 2:1 CIR samples.

\section{Abbreviations}

CIR: Crown-to-implant ratio; $F_{\text {max }}$ : Maximum compression force; IP: Implantoplasty; ISO: International Organization for Standardization; PI: Peri-implantitis; R1: Length at middle of the first thread; R2: Length at middle of the tenth thread; R3: Length at the end of prosthetic screw hole; SD: Standard deviation; SEM: Scanning electron microscopy.

\section{Acknowledgements}

The authors wish to thank Anton Galigrov (Compression tests. Industrial engineer at Avinent ${ }^{\circledR}$ Implant System, Santpedor, Spain), the staff of Centres Científics i Tecnológics of the University of Barcelona (SEM screening), Mary Georgina Hardinge (English language editing assistance) and Professor Mário Vaz (Critical review. School of Engineering, Oporto University, Portugal).

\section{Authors' contributions}

BLA: design of the study; acquisition and interpretation of the data; drafting of the article; approval of the final version of the manuscript and agreement to be accountable for all aspects of the work; RF: Conception and design of the study; interpretation of the data; drafting of the article; approval of the final version of the manuscript and agreement to be accountable for all aspects of the work; AC: Conception of the study; interpretation of the data; critical review of the article; approval of the final version of the manuscript and agreement to be accountable for all aspects of the work; OCF: Conception of the study; analysis and interpretation of the data; critical review of the article; approval of the final version of the manuscript and agreement to be accountable for all aspects of the work; JMM: Conception of the study; interpretation of the data; critical review of the article; approval of the final version of the manuscript and agreement to be accountable for all aspects of the work; EVC: Design of the study; analysis and interpretation of the data; critical revision of the manuscript; approval of the final version of the manuscript and agreement to be accountable for all aspects of the work. All authors read and approved the final manuscript. 


\section{Funding}

The present research was conducted by the Dental and Maxillofacial Pathology and Therapeutics research group at IDIBELL (Barcelona, Spain). The Center of Interdisciplinary Research in Health of Universidade Católica Portuguesa (Viseu, Portugal) also supported this study with non-financial aid. This study was partially funded by the Cátedra UB-AVINENT. Funding body did not have any role in the design of the study, collection, analysis and interpretation of the data or in the writing of the manuscript. Funding consisted on logistical support and access to instruments and materials needed for study implementation.

\section{Availability of data and materials}

The datasets used and analyzed during the current study are available from the corresponding author on reasonable request.

\section{Ethics approval and consent to participate}

This article does not report on any studies with human or animal participants and formal consent is not required.

\section{Consent for publication}

Not applicable.

\section{Competing interests}

The authors declare non-financial support from Avinent (Santpedor, Spais) for this study. The authors would like to declare the following interests outside the work presented: BLA reports personal fees (sponsored lectures) and nonfinancial support from Megagen (Daegu, South Korea) outside the submitted work. RF reports personal fees (sponsored lectures) from Inibsa Dental (Lliça de Vall, Spain). In addition, he has participated as a sub-investigator in a randomized clinical trial sponsored by Mundipharma (Cambridge, UK) and another clinical trial for Menarini Ricerche (Florence, Italy). AC reports personal fees (sponsored lectures) from Straumann (Basel, Switzerland). JMM reports no conflicts of interest. OCF reports grants, personal fees (sponsored lectures) and non-financial support from MozoGrau (Valladolid, Spain), and personal fees (sponsored lectures) from BioHorizons Ibérica (Madrid, Spain), Inibsa Dental (Lliça de Vall, Spain), Dentsply implants Iberia (Barcelona, Spain) and Araguaney Dental (Barcelona, Spain) outside the submitted work. He has also participated as a principal investigator in a randomized clinical trial sponsored by Mundipharma (Cambridge, UK) and in another clinical trial as a sub-investigator for Menarini Ricerche (Florence, Italy). EVC reports personal fees (sponsored lectures) and non-financial support from MozoGrau (Valladolid, Spain), and personal fees (sponsored lectures) from BioHorizons Ibérica (Madrid, Spain), Inibsa Dental (Lliça de Vall, Spain) and Dentsply implants Iberia (Barcelona, Spain) outside the submitted work. In addition, he has participated as a sub-investigator in a randomized clinical trial sponsored by Mundipharma (Cambridge, UK)

\section{Author details}

${ }^{1}$ Faculty of Dental Medicine, Center for Inter-Disciplinary Research in Health (CIIS), Universidade Católica Portuguesa, Estrada da Circunvalação, 3504-505 Viseu, Portugal. ${ }^{2}$ Oral Surgery and Implantology, Faculty of Medicine and Health Sciences, University of Barcelona, Barcelona, Spain.

Received: 23 June 2020 Accepted: 10 November 2020

Published online: 19 November 2020

\section{References}

1. Ramanauskaite A, Daugela P, de Almeida RF, et al. Surgical non-regenerative treatments for peri-implantitis: a systematic review. J Oral Maxillofac Res. 2016;7:1-11.

2. Figuero E, Graziani F, Sanz I, et al. Management of peri-implant mucositis and peri-implantitis. Periodontol 2000. 2014;66:255-73.

3. Heitz-Mayfield LJA. Peri-implant diseases: diagnosis and risk indicators. J Clin Periodontol. 2008;35:292-304.

4. Kordbacheh Changi K, Finkelstein J, Papapanou PN. Peri-implantitis prevalence, incidence rate, and risk factors: a study of electronic health records at a US dental school. Clin Oral Implants Res. 2019;30:306-14.
5. Tawse-Smith A, Kota A, Jayaweera Y, et al. The effect of standardised implantoplasty protocol on titanium surface roughness: an in-vitro study. Braz Oral Res. 2016;30(1):e137.

6. Smeets $\mathrm{R}$, Henningsen $\mathrm{A}$, Jung $\mathrm{O}$, et al. Definition, etiology, prevention and treatment of peri-implantitis-a review. Head Face Med. 2014;10:34.

7. Esposito M, Grusovin MG, Kakisis I, et al. Interventions for replacing missing teeth: treatment of perimplantitis. Cochrane Database Syst Rev. 2008;52(2):CD005970

8. Schwarz F, John G, Schmucker A, et al. Combined surgical therapy of advanced peri-implantitis evaluating two methods of surface decontamination: a 7-year follow-up observation. J Clin Periodontol. 2017:44:337-42.

9. Chan H, Lin G, Suarez F, et al. Surgical management of peri-implantitis: a systematic review and meta-analysis of treatment outcomes. J Periodontol. 2014;85:1027-41.

10. Stavropoulos A, Bertl K, Eren S, et al. Mechanical and biological complications after implantoplasty - a systematic review. Clin Oral Implants Res. 2019;30:833-48.

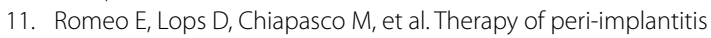
with resective surgery. A 3-year clinical trial on rough screw-shaped oral implants. Part II: radiographic outcome. Clin Oral Implants Res. 2007;18:179-87.

12. Cortés-Acha B, Figueiredo R, Blanc V, et al. Development and viability of biofilms grown on experimental abutments mimicking dental implants: an in vivo model. Med Oral Patol Oral Cir Bucal. 2019;24:e511-7.

13. Renvert S, Polyzois I, Claffey N. Surgical therapy for the control of periimplantitis. Clin Oral Implants Res. 2012;23:84-94.

14. Sharon E, Shapira L, Wilensky A, et al. Efficiency and thermal changes during implantoplasty in relation to bur type. Clin Implant Dent Relat Res. 2013;15:292-6.

15. Chan $\mathrm{H}-\mathrm{L}, \mathrm{O}$ W-S, Ong HS, et al. Impact of implantoplasty on strength of the implant-abutment complex. Int J Oral Maxillofac Implants. 2013;28(6):1530-5.

16. Olmedo DG, Nalli G, Verdú S, et al. Exfoliative cytology and titanium dental implants: a pilot study. J Periodontol. 2013:84:78-83.

17. Fretwurst $T$, Buzanich $G$, Nahles $S$, et al. Metal elements in tissue with dental peri-implantitis: a pilot study. Clin Oral Implants Res. 2016;27:1178-86.

18. Safioti LM, Kotsakis GA, Pozhitkov AE, et al. Increased levels of dissolved titanium are associated with peri-implantitis-a cross-sectional study. J Periodontol. 2017:88:436-42.

19. Suárez-López del Amo F, Garaicoa-Pazmiño C, Fretwurst T, et al. Dental implants-associated release of titanium particles: a systematic review. Clin Oral Implants Res. 2018;29:1085-100.

20. Sánchez-Pérez A, Moya-Villaescusa MJ, Jornet-García A, et al. Etiology, risk factors and management of implant fractures. Med Oral Patol Oral Cir Bucal. 2010;15:e504-8.

21. Suzuki H, Hata Y, Watanabe F. Implant fracture under dynamic fatigue loading: influence of embedded angle and depth of implant. Odontology. 2016;104:357-62.

22. Bertl K, Isidor F, von Steyern PV, Stavropoulos A. Does implantoplasty affect the failure strength of narrow and regular diameter implants? A laboratory study. Clin Oral Invest. 2020. https://doi.org/10.1007/s0078 4-020-03534-8

23. International Association for Standardization. ISO No. 14801:2016 Dentistry -implants - dynamic loading test for endosseous dental implants. Geneva: ISO; 2016.

24. Gehrke SA. Importance of crown height ratios in dental implants on the fracture strength of different connection designs: an in vitro study. Clin Implant Dent Relat Res. 2015;17:790-7.

25. Costa-Berenguer X, García-García M, Sánchez-Torres A, et al. Effect of implantoplasty on fracture resistance and surface roughness of standard diameter dental implants. Clin Oral Implants Res. 2018;29:46-54.

26. Camps-Font O, González-Barnadas A, Mir-Mari J, et al. Fracture resistance after implantoplasty in three implant-abutment connection designs. Med Oral Patol Oral Cir Bucal. 2020;25(5):e691-699.

27. Tribst JPM, Dal Piva AM, de O, Shibli JA, et al. Influence of implantoplasty on stress distribution of exposed implants at different bone insertion levels. Braz Oral Res. 2017;31:e96.

28. Shemtov-Yona K, Rittel D, Levin L, et al. Effect of dental implant diameter on fatigue performance. Part I: mechanical behavior. Clin Implant Dent Relat Res. 2014:16:172-7. 
29. Schwarz F, John G, Becker J. The influence of implantoplasty on the diameter, chemical surface composition, and biocompatibility of titanium implants. Clin Oral Investig. 2017;21(7):2355-61.

30. Prados-Privado M, Gehrke SA, Rojo R, et al. Probability of failure of internal hexagon and morse taper implants with different bone levels: a mechanical test and probabilistic fatigue. Int J Oral Maxillofac Implants. 2018;33(6):1266-73

31. Hattori Y, Satoh C, Kunieda T, et al. Bite forces and their resultants during forceful intercuspal clenching in humans. J Biomech. 2009:42:1533-8.

32. Gibbs $\mathrm{CH}$, Anusavice $\mathrm{KJ}$, Young $\mathrm{HM}$, et al. Maximum clenching force of patients with moderate loss of posterior tooth support: a pilot study. J Prosthet Dent. 2002;88:498-502.
33. Umesh S, Padma S, Asokan S, et al. Fiber Bragg grating based bite force measurement. J Biomech. 2016:49:2877-81.

\section{Publisher's Note}

Springer Nature remains neutral with regard to jurisdictional claims in published maps and institutional affiliations.
Ready to submit your research? Choose BMC and benefit from:

- fast, convenient online submission

- thorough peer review by experienced researchers in your field

- rapid publication on acceptance

- support for research data, including large and complex data types

- gold Open Access which fosters wider collaboration and increased citations

- maximum visibility for your research: over $100 \mathrm{M}$ website views per year

At BMC, research is always in progress.

Learn more biomedcentral.com/submissions 